\title{
Thermodynamical evaluation of usefulness of future hydrocarbon fuels for use in compression ignition engines
}

\author{
Ireneusz Pielecha ${ }^{1}$ (D) Krzysztof Wisłocki $^{1} \cdot$ Przemysław Borowski $^{1} \cdot$ \\ Wojciech Cieślik ${ }^{1}$
}

Received: 8 December 2014/Accepted: 30 April 2015/Published online: 16 May 2015

(c) The Author(s) 2015. This article is published with open access at Springerlink.com

\begin{abstract}
The paper discusses the issues of the influence of the fuel spray formation on the generation of self-ignition spots and the development of pre-flame processes in the cylinder of a model diesel engine. The investigations were carried out for a standard diesel fuel and two other types of fuel that were mixtures of ethanol, butanol, and diethylether in a variety of proportions. By applying optical methods of analysis, the authors determined the geometrical indexes of the injected fuel spray as well as fuel mass distribution in the longitudinal and transverse cross section of the fuel spray during the injection process. The location and number of the self-ignition spots in the combustion chamber were evaluated on the basis of a comparison under various conditions: in presence of the charge swirl and at the lack of it. Research conducted for the single-cylinder engine confirmed the possibility of the use of diesel-like fuels for compression ignition engines.
\end{abstract}

Keywords Diesel fuel injection · Atomization · Self-ignition · Alternative fuels

\section{Introduction}

The well-known and recognized influence of automotivebased $\mathrm{CO}_{2}$ emissions on the climate indicates the necessity of improving the efficiency of passenger cars. Despite the tendency toward hybrid and full electric systems, the internal combustion engines will remain the essential part of

Ireneusz Pielecha

ireneusz.pielecha@put.poznan.pl

1 Poznan University of Technology, Poznan, Poland automotive industry in the next decades. Hence, the efficiency of these engines needs to be improved to create a noticeable positive effect on the worldwide $\mathrm{CO}_{2}$ emission [1].

The need to comply with exhaust emission standards will force the search for alternative fuels to power the compression ignition (CI) engines. At the same time, expected reduction of carbon dioxide emissions into the atmosphere makes it desirable to apply ethanol, butanol, and gasoline as additives to diesel fuel. Mixtures of these fuels have properties similar to diesel fuel and even, in some aspects, surpass them. The paper contains an assessment of the applicability of such mixtures of fuels with respect to their properties for atomization, evaporation, and further combustion.

The tests conducted by the authors [2] involving the use of diesel fuel confirmed essential role of pre-flame processes in the process of combustion and formation of harmful components of exhaust gases.

The tests on atomization and combustion of alternative fuels (ethanol, biofuels) were published by the authors in articles [3, 4] and [5]. In paper [6], the geometrical dependence between the localization of injector in relation to the piston was pointed out [7]. By applying the injector at different depths, it is possible to change the way the fuel is sprayed and distributed in the cylinder, which is vital for the atomization and combustion process.

Analysis of literature concerning application of practical alternative fuels (being mixtures of ethanol, butanol and other components) shows some significant aspects of this problem:

(a) Application of ethanol as an additive to diesel fuel at a rate of $10-15 \%$ results in lowering of PM emission by $20-27 \%$ and $30-41 \%$, respectively [8]. Such mixture has lower density, lower cetane 
number, and lower viscosity $[9,10]$. The important barrier in application of this kind of mixtures is the limited mixing ability in lower temperatures. Some research works are being currently performed to work out the new fuel additives which would allow to preserve the homogeneity of the diesel fuel and ethanol mixtures independent of the temperature;

(b) Addition of the butanol additive to diesel fuel in amount of $10 \%$ reduces the cetane number of the mixture by $7 \%$ in comparison with diesel fuel [11]; small addition of diethylhexyl nitrate $(0.1 \%)$ results in the improvement of cetane number, which reduces self-ignition delay of the fuel. Analysis of the butanol additive (5-20\%) to diesel fuel performed by Kinoshita [12] showed an increase in self-ignition delay compared with the diesel fuel; however, the improvement in thermal efficiency of the combustion process has been confirmed.

(c) Application of the diethylether (DDE) as an additive to diesel fuel allows for the reduction of self-ignition delay due to the high cetane number of DDE. Investigations performed by Biradar [13], where 5-10 \% DDE stand for additive to diesel fuel, have indicated an increase in maximal cylinder pressure and of maximal values of heat release rates. Experiments conducted by Iranmanesh for DDE additive amounting up to $10 \%$ [14] and up to $20 \%$ [15] have shown a significant decrease in $\mathrm{NO}_{\mathrm{x}}$ emission (up to $51 \%$ ) for higher DDE rates. The smaller fuel viscosity achieved in this way leads to the improvement of fuel atomization and combustion process; however, it does not improve the PM emission, and there has been recorded even higher $\mathrm{CO}$ emission. Similar results were obtained by Cui et al. [16] in which the application of ethanol and diesel fuel mixtures has contributed to decrease in $\mathrm{PM}$ and $\mathrm{NO}_{\mathrm{x}}$ emissions and simultaneous increase in the $\mathrm{CO}$ and hydrocarbons emissions. Despite the use of more volatile ethanol, for low engine loads, the self-ignition delay increased compared with diesel fuel.

According to the examples discussed above, the content of additives in the base fuel is usually restricted to small values. Only in case of ethanol, application in bigger content could be considered.

To meet future emission limits, such fuel properties are required, which allow to decrease fuel density at the expense of only a small reduction of fuel calorific value. It is also required to reduce the viscosity of fuel in order to facilitate its dispersion during the injection. The use of alternative fuels (or fuel mixtures) should make it possible to burn them with a large participation of recirculated exhaust gases. This requirement can be met only in the case of fuels with reduced tendency to form particulate matter and thus are more volatile. In this case, it is indicated to use additives to diesel fuel in the form of components (e.g., ethanol, butanol, or DEE).

The use of alternative fuels (or additives) results in the changes in atomization and combustion process at a later stage. Research conducted by Park [17] indicates that the high ambient gas pressure results in the fast breakup of droplets and the small droplet size. In comparison of D100 (diesel fuel) and DE20 fuels (diesel-80\%, ethanol $20 \%$ ), the droplet size of DE20 fuel was smaller than that of D100 fuel due to the low kinematic viscosity and surface tension.

The evaporation of liquid droplets has essential influence on the ignition, combustion, and exhaust emissions as well as the atomization characteristics of spray and the mixing process of air and fuel droplets [18]. The authors of the paper [19] stated that DE20 fuel started to evaporate earlier, and its final vaporized fuel mass was also larger than that of D100. It is due to the fact that the volatility of DE20 is superior to that of D100, and the active energy to evaporate for DE20 is lower than that for D100. In addition, the high injection pressure in both fuels resulted in the fast and large evaporation due to the active atomization.

A study of ignition delay carried out with the use of fuels with similar cetane numbers was reported in the paper [20]. A mixture of ethanol and butanol with the diesel fuel has been used for this purpose with its cetane number $(\mathrm{CN})$ of 35 (40\% ethanol or butanol $55 \%)$ and $\mathrm{CN}=40(30 \%$ ethanol and $40 \%$ butanol). No significant differences in self-ignition delay have been observed at variable engine loads for the fuels with the same cetane number.

Research on the course of combustion process is very important regarding the application of new alternative fuels, e.g., the biodiesel produced by transesterification of soybean oil [21], rapeseed oil, and biomass [22], which can be used instead conventional ones.

The author's work, based on previous knowledge concerning these fuels, allowed for an assessment of the spray formation and atomization processes in terms of their geometrical indexes. Research on pre-flame processes was designed to determine the capability of self-ignition based on local values of indexes of the combustion process.

\section{Methodology of research}

\section{Investigated fuels}

Research on the fuel atomization and generation of selfignition spots was conducted for diesel fuel and for mixtures of diesel fuel (DF) with butanol (BUT) and ethanol (E20-20\% ethanol $+80 \%$ gasoline, E100-100\% 
ethanol). These fuels have been marked as F1, F2, and F3, and their basic indicators are shown in Table 1. One can notice that for every fuel in order from $\mathrm{F} 1$ to $\mathrm{F} 3$, the calorific value is reduced by ca. $13 \%$, their density by ca. $3 \%$, and viscosity by ca. $45 \%$. Ethanol additive to diesel fuel significantly reduces the viscosity and density of the mixture; for this reason, in this case, the better and faster fuel atomization and shortened self-ignition delay were expected.

\section{Test stands}

Studies on the issues affecting fuel atomization and preflame combustion require analysis of the injection and combustion processes with the use of appropriate test stands. An analysis of the injection process, the formation of sprays, and liquid fuel distribution in sprays was carried out using a constant volume chamber (with back-pressure adjustable in a wide range of values), which is schematically shown in Fig. 1. The test stand enabled conducting tests for two mounting positions of the injector. Due to this, it was possible to record the fuel injection for axial and radial position of the injector against the camera.

To determine the self-ignition delay, as well as the number and locations of self-ignition spots, the rapid compression machine (RCM) has been used, which is presented in Fig. 2. A transparent piston used in the machine enabled recording the combustion process with the use of a highspeed camera LaVision HSS5. After processing the recorded images, it was possible to determine self-ignition spots and early flame propagation for hydrocarbon fuels for variety of injection pressures and fuel doses.

The bench tests were conducted with the use of singlecylinder research engine, the scheme of which is shown in

Table 1 Characteristics of investigated fuels

\begin{tabular}{|c|c|c|c|}
\hline $\begin{array}{l}\text { Fuel } \\
\text { Composition }\end{array}$ & $\begin{array}{l}\text { F1 } \\
\text { Diesel fuel }\end{array}$ & $\begin{array}{l}\mathrm{F} 2 \\
70 \% \text { Diesel fuel } 30 \% \text { E20 } \\
\% \text { ethanol }+80 \% \text { gasoline }\end{array}$ & $\begin{array}{l}\text { F3 } \\
45 \% \text { Diesel fuel, } 45 \% \text { butanol } \\
10 \% \text { diethylether (DDE) }\end{array}$ \\
\hline Calorific value $C / \mathrm{MJ} \mathrm{Kg}^{-1}$ & 42.87 & 41.58 & 37.46 \\
\hline Density $\rho \mathrm{kg} \mathrm{m}^{-3}$ & 835 & 813 & 812 \\
\hline Viscosity $v / \mathrm{mPa} s$ & 2.95 & 1.59 & 1.62 \\
\hline Air access ratio (stoichiometric) $\lambda /-$ & 14.53 & 14.21 & 12.85 \\
\hline
\end{tabular}

Fig. 1 The scheme of constant volume chamber for investigations of fuel injection and atomization

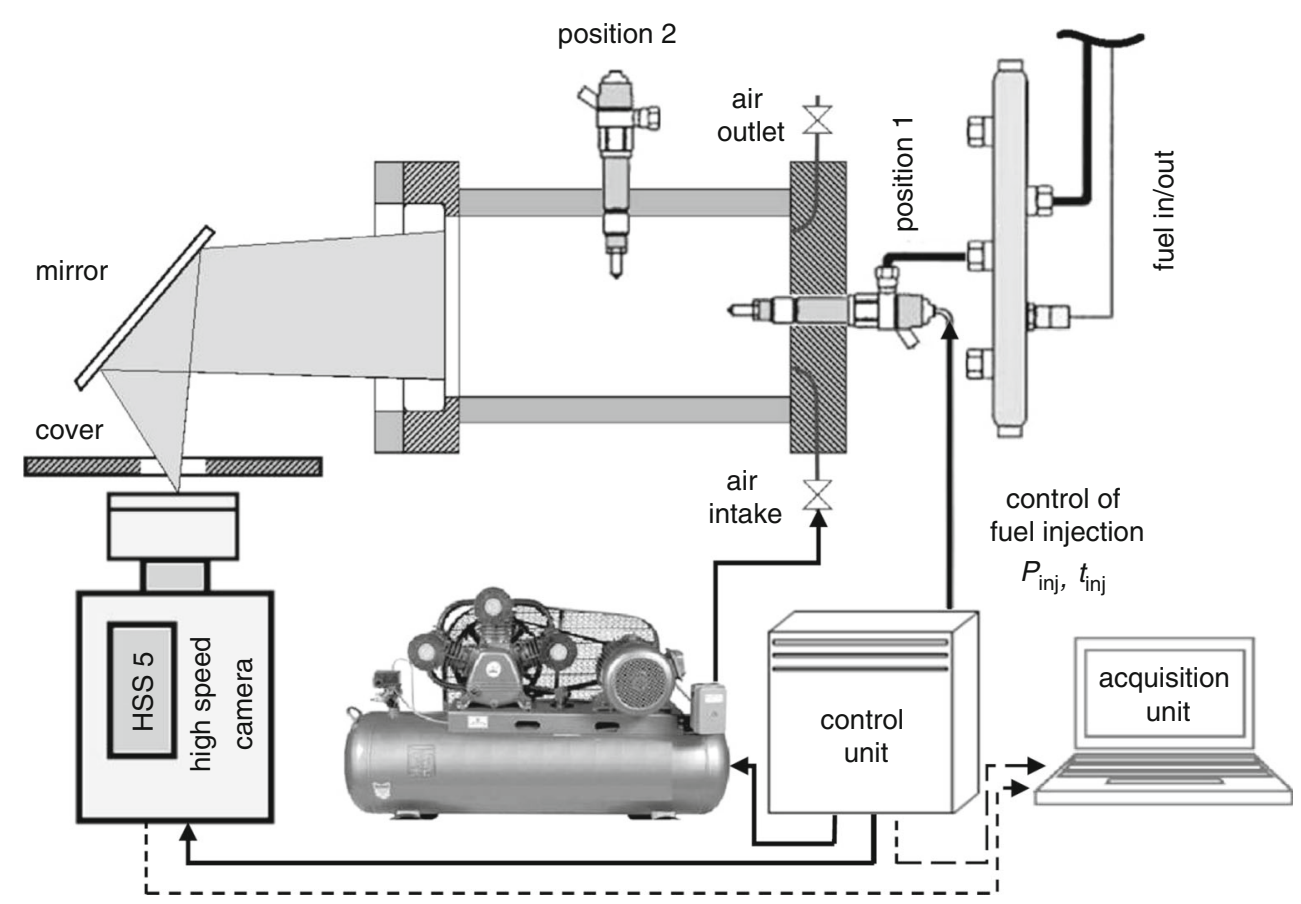



combustion chamber of the rapid compression machine
Fig. 2 Optical access into

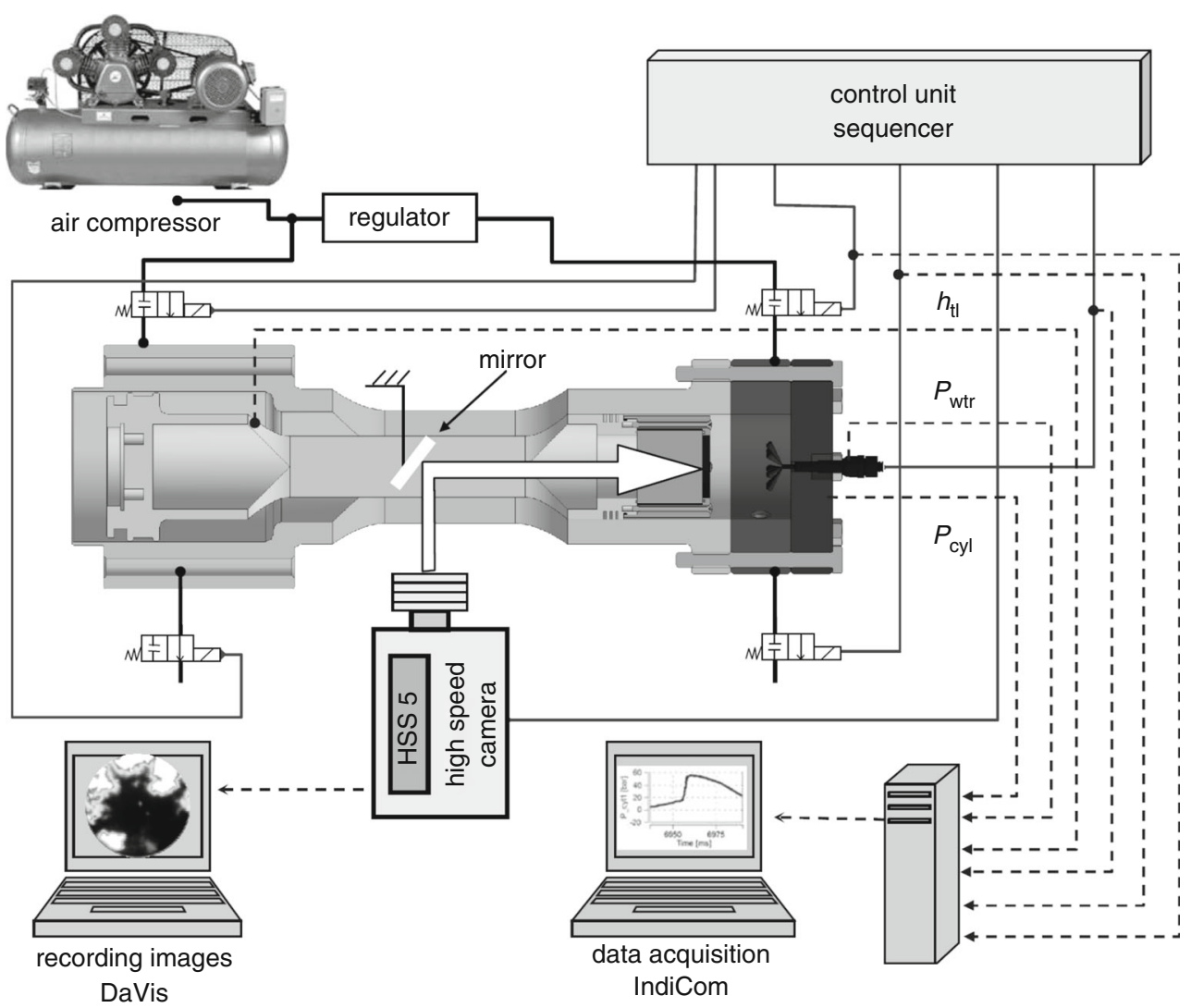

Fig. 3 Single-cylinder research engine-test stand

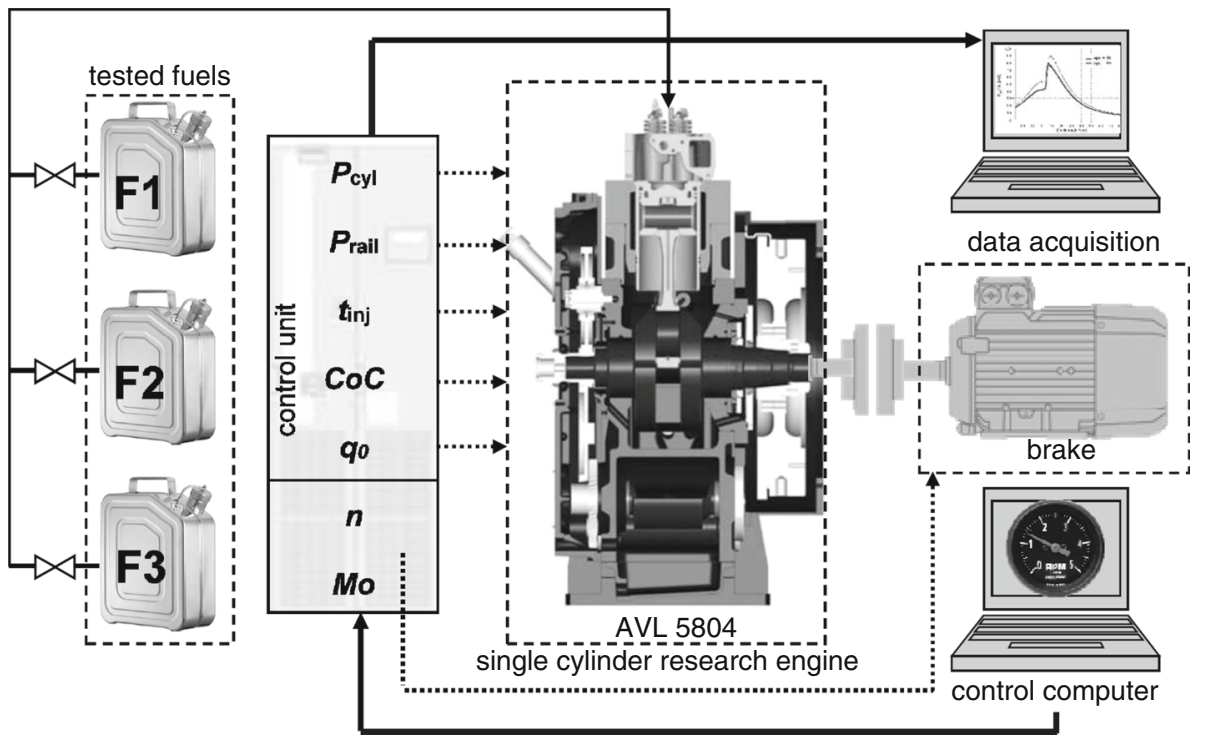

Fig. 3. Application of the measuring apparatus for measuring fast-varying processes enabled the thermodynamic assessment of the combustion process, including the selfignition delay, heat release rate, and amount of heat released as well as of the uniformity of engine operation. The engine tests explained also the levels of emissions of harmful components of exhaust gases for engines fueled with the tested hydrocarbon fuels. 
Table 2 Test plan of investigations in the constant volume chamber

\begin{tabular}{lllc}
\hline$P_{\text {inj }} / \mathrm{MPa}$ & $t_{\text {inj }} / \mathrm{ms}$ & $P_{\text {back }} / \mathrm{Mpa}$ & $q_{\mathrm{o}} / \mathrm{mg}$ \\
\hline 80 & 0.3 & 3 & 8 \\
100 & 0.7 & 3 & 31 \\
\hline
\end{tabular}

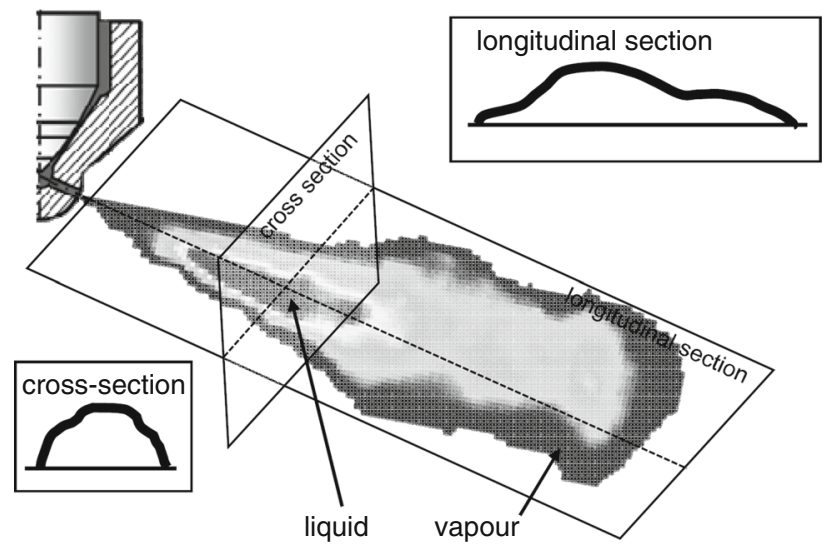

Fig. 4 Methodology of research of the fuel distribution in crosssectional and longitudinal section of fuel spray

\section{Range of research}

In order to obtain the comparative results, the research was carried out for two different values of injection pressure and for two fuel injection duration times. During most of the measurements, constant back-pressure equal to $3 \mathrm{MPa}$ has been maintained in the workspace. Different injection pressures and injection duration times have resulted in different values of injected fuel doses, ranging from 8 to $31 \mathrm{mg}$. Test plan of investigations on injection performed in the constant volume chamber is presented in Table 2.

\section{Rules of interpretation of the results of research on fuel atomization}

In the assessment of the injection process and injected fuel distribution, geometric indexes have been applied, evaluated on the basis of an assessment of the amount of light reflected from the droplets of fuel. On this basis, the droplet distribution within the observed space has been identified and interpreted. The analysis includes the following indicators: fuel spray penetration and fuel spray area (its planar exposition). Spray penetration was being determined as an average of eight (the number of injector holes) fuel sprays recorded at the same time. Fuel spray area refers to the area (its planar exposition) covered by droplets glowing with reflected light of a defined level of luminance; this area was determined as a total for all sprays of injected fuel (here with 8 holes in injector).
Analysis of the distribution of fuel in cross and longitudinal planes was made for a single fuel spray in order to obtain real values, and not the average ones (see Fig. 4). The distance from the axis of the injector to the cross section of spray under analysis was $72 \mathrm{pix}=14.4 \mathrm{~mm}$.

\section{Research on fuel atomization}

\section{Influence of injection pressure on fuel spray geometrical indexes}

Investigations on fuel spray atomization were carried out in a constant volume chamber. Sample pictures of sprays of different fuels at $0.4 \mathrm{~ms}$ after the start of injection (SOI) are shown in Fig. 5. The investigated fuels have been chosen for their different physical properties (Table 1), which allowed for an assessment of the impact of these properties on the changes in fuel atomization process, and their later combustion. For comparison purposes, the medium value of spray penetration for different fuels has been determined as well as the area covered by the fuel aerosol; such a comparison is shown in chapter 4.2.

\section{Influence of injection pressure on fuel distribution along cross- and longitudinal section of the spray}

Investigations of fuel spray geometry (spray penetration and spray area) have been supported by the analysis of luminance of light reflected by fuel droplets in cross- and longitudinal section of sprays. It was assumed that the light luminance could stand for the measure of the fuel droplets concentration in the observed area. In Fig. 6, the comparison of such distributions in cross sections of spray for two times after SOI has been presented, namely for $t=0.5 \mathrm{~ms}$ and $t=0.8 \mathrm{~ms}$. Such comparison has been conducted for all investigated fuels: from F1 to F3. This comparison shows that after the time of $0.3 \mathrm{~ms}$, the luminance of fuel droplets is getting significantly reduced for fuel F2. These fuels contain ethanol, which significantly influences on the reduction of fuel concentration in the spray core.

Increase in the fuel injection pressure up to $100 \mathrm{MPa}$ and elongation of the injection time to $0.7 \mathrm{~ms}$ result in similar observations (Fig. 7). F3 fuel still has the smallest spray luminance, which points to the rapid growth of the volatile phase (evaporation) in the fuel. With the increasing injection time increases the fuel quantity dispensed by the injector. A large mass of fuel causes the fuel distribution in fuel sprays after 0.5 and $0.8 \mathrm{~ms}$ after SOI does not bring substantial changes. Due to the increased fuel dose, after the time of $0.8 \mathrm{~ms}$, the fuel concentration in spray is increased, resulting in the delayed evaporation. 
Fig. 5 Spray formation for different fuels at injection pressure $100 \mathrm{MPa}$; injection time $t_{\text {inj }}=0.7 \mathrm{~ms}$; time after $\mathrm{SOI}=0.4 \mathrm{~ms}$
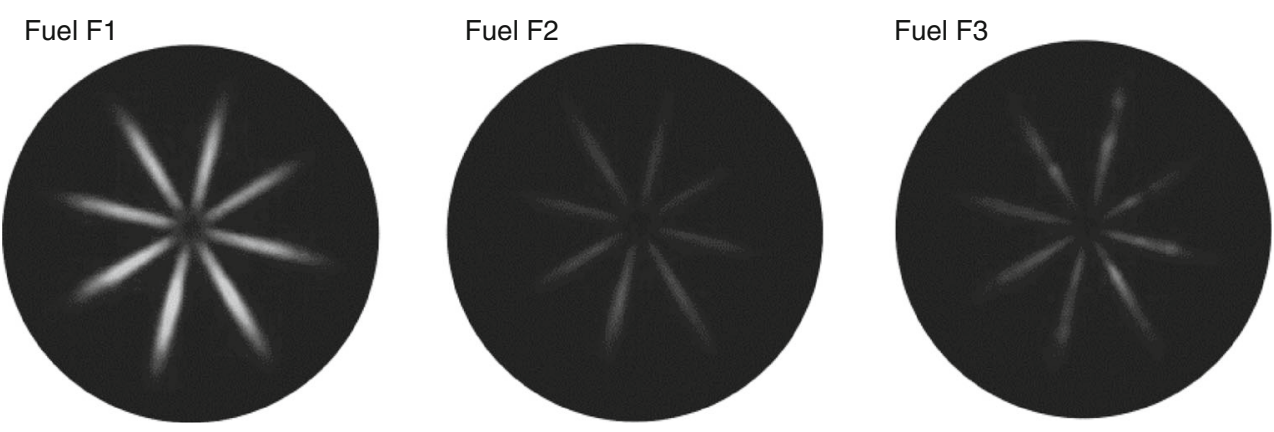

Fig. 6 Fuel concentration distribution in cross section of the sprays of different fuels; injection pressure

$P_{\text {inj }}=80 \mathrm{MPa}$, back-pressure $3 \mathrm{MPa}, t=0.5 \mathrm{~ms}$ and $0.8 \mathrm{~ms}$ after SOI for a section at $l=14.4 \mathrm{~mm}$ from center of injector (COI)

Fig. 7 Fuel concentration distribution in the cross section of sprays of different fuels for $P_{\text {inj }}=100 \mathrm{MPa}$; back-pressure in the chamber- $3 \mathrm{MPa}$, $t=0.5 \mathrm{~ms}$ and $0.8 \mathrm{~ms}$ after SOI for a section at $l=14.4 \mathrm{~mm}$ from COI
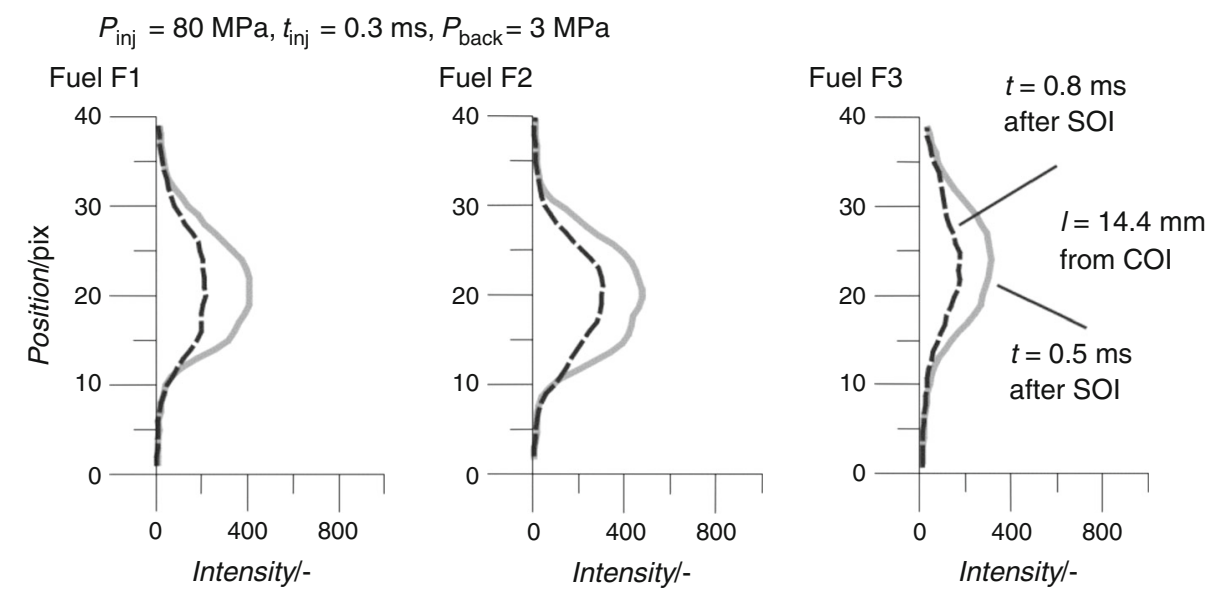

$$
P_{\text {inj }}=100 \mathrm{MPa}, t_{\text {inj }}=0.3 \mathrm{~ms}, P_{\text {back }}=3 \mathrm{MPa}
$$

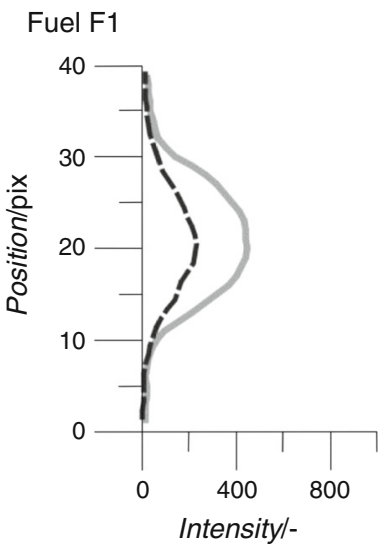

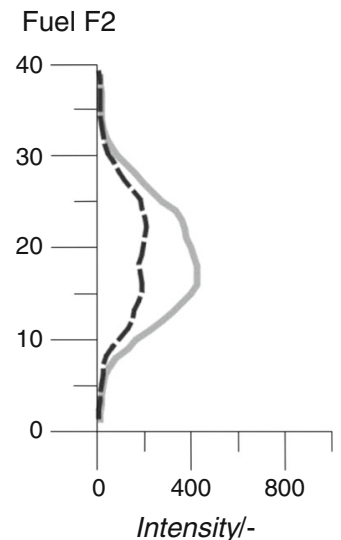

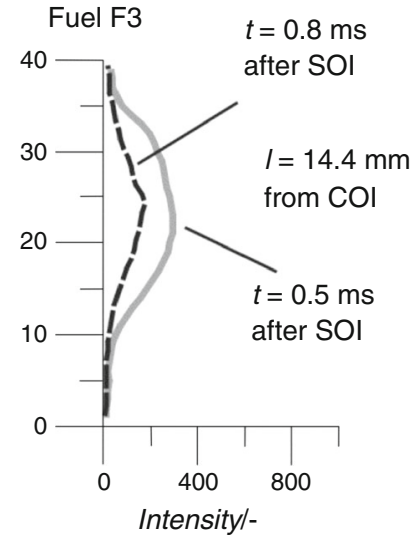

Analysis of fuel distribution in the cross section of spray for fuel F3 (a mixture of diesel fuel, butanol and DEE) shows its concentration significantly lower (Figs. 6, 7) regardless of the time of observation. Despite the fact that the density of this fuel $\left(\rho=805 \mathrm{~kg} \mathrm{~m}^{-3}\right)$ differs a little from the density of fuel F2 $\left(\rho=813 \mathrm{~kg} \mathrm{~m}^{-3}\right)$, the 
Fig. 8 Fuel mass distribution in the longitudinal section of the spray of different fuels; chamber back-pressure MPa, injection pressure $P_{\text {inj }}=80 \mathrm{MPa}$, injection duration $t_{\text {inj }}=0.3 \mathrm{~ms}$

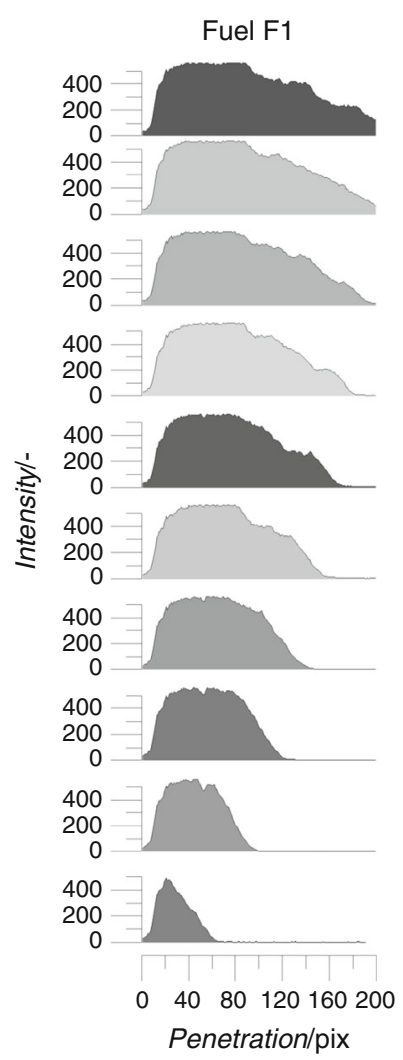

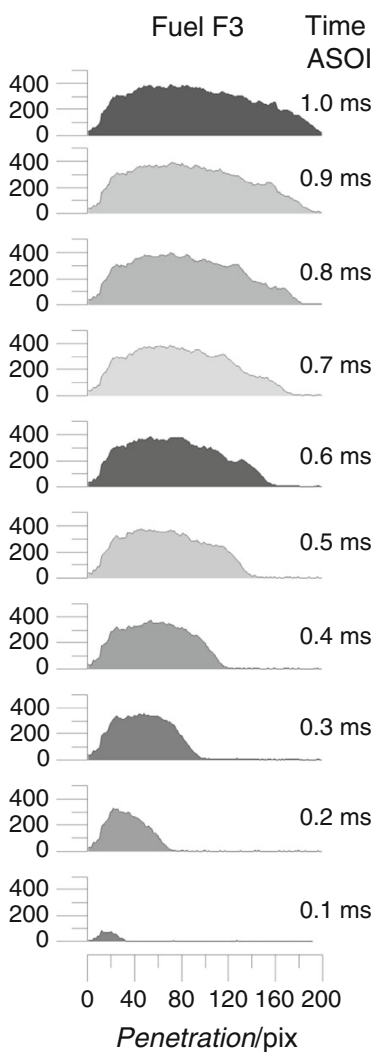

distribution of fuel in the spray cross section indicates greater volatility, expressed in a lower luminance of fuel drops in this section.

It should be noted that this fuel has in its composition $45 \%$ of butanol. Previous observations have been also confirmed by the analysis of the longitudinal sections. It is apparent from it that the fuel F3 indicates the smallest fuel concentration in this section, which is indicated by low luminance value (Fig. 8). This phenomenon is observed particularly intensively during the atomization process for $t>0.5 \mathrm{~ms}$.

Increasing the fuel injection pressure up to $100 \mathrm{MPa}$ and elongation of the injection duration up to $t_{\text {inj }}=0.7 \mathrm{~ms}$ result in similar changes. F3 fuel shows the smallest luminance values (Fig. 9), which proves its significant evaporation. However, the decrease in luminance is definitely smaller than in case of the lower injection pressure of $80 \mathrm{MPa}$.

With diversified atomization of these fuels, differences in their flammability and pre-flame processes might also be expected. To determine those differences, the research of self-ignition delay was carried out in the rapid compression machine. The results of these tests are shown below.

\section{Determination of self-ignition ability of tested fuels}

Self-ignition delay of hot flames was defined as the time counted from the moment in which in the image appears fuel at the tip of the injection nozzle until the moment in which in the image appears the first outbreak of a hot flame, which ensures a further continuous flame development. The method of recording the self-ignition delay is burdened with error equal to half of the time interval between subsequent images; by the application of filming frequency of 60,000 frames per second, this time amounts to $<8.3 \mu \mathrm{s}$.

An example of a sequence of images for the assessment of self-ignition delay of hot flames is shown in Fig. 10.

A research on the phenomenon of the self-ignition and combustion process was carried out by adjusting injection duration time to equal the energy contained in fuel (for different fuels with different calorific values). The fuel dose at a pressure of $50 \mathrm{MPa}$ had $16.6 \mathrm{mg}$ (energy equal to $Q=713 \mathrm{~J}$ ) and at a pressure of $100 \mathrm{MPa}-9.3 \mathrm{mg}$ (energy equal to $Q=398 \mathrm{~J}$ ). These values correspond to the equivalent energy of diesel fuel. 
Fig. 9 Fuel mass distribution in the longitudinal section of the spray of different fuels; chamber back-pressure $3 \mathrm{MPa}$, injection pressure $P_{\text {inj }}=100 \mathrm{MPa}$, injection duration $t_{\mathrm{inj}}=0.7 \mathrm{~ms}$

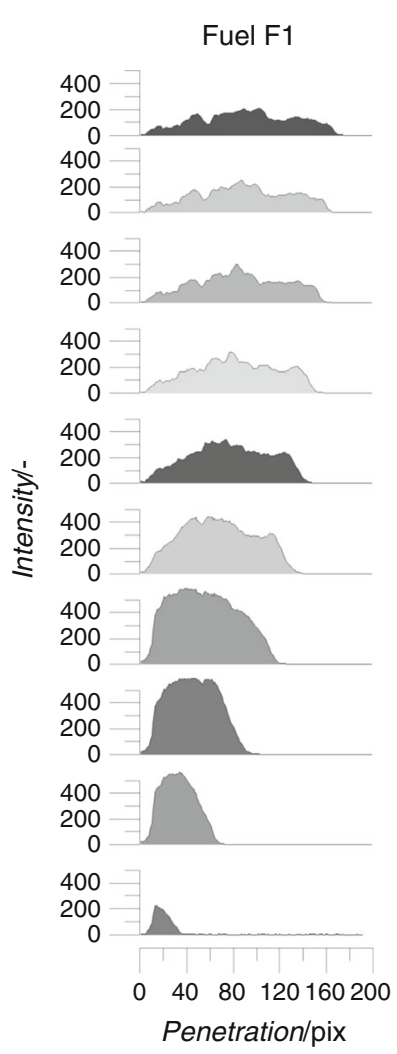

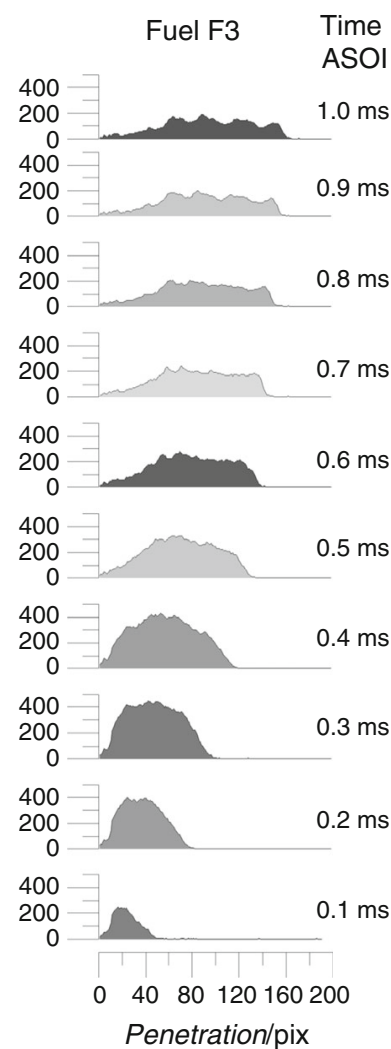

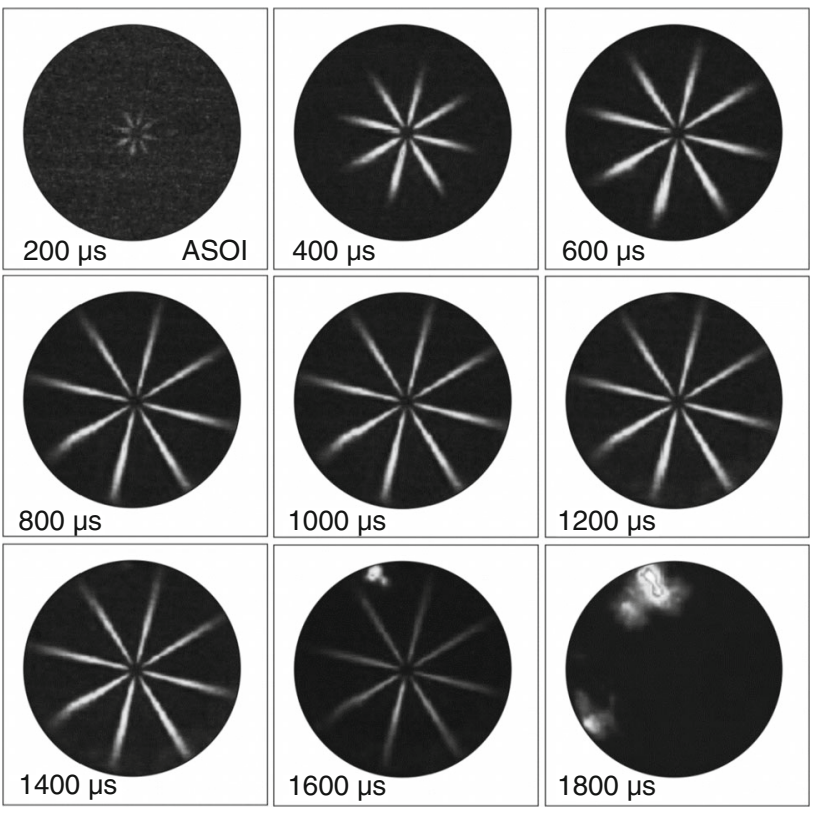

Fig. 10 Sequence of images showing the method of determining of the self-ignition delay of hot flames $\left(P_{\mathrm{inj}}=100 \mathrm{MPa}, t_{\mathrm{inj}}=0.5 \mathrm{~ms}\right.$, fuel F3)
In Fig. 11, two images are presented: the first one showing the first self-ignition spots and the other depicting further development of these spots into regular flame.

The comparison was made for a single dose of fuel injected, for two cases of fuel injection pressure $P_{\text {inj }}=50 \mathrm{MPa}$ (images on the left side) and $100 \mathrm{MPa}$ (right side), for which the time of self-ignition of hot flames ( $t_{\mathrm{SOC}}$ - time of start of combustion) has been determined and then related to the time of the SOI $\left(t_{\mathrm{SOI}}=0.0\right)$. This value is specified as the self-ignition delay of individual fuels.

From the images presented in Fig. 11, it could be concluded that the short self-ignition delay occurs for the injection of F2 fuel, regardless of injection pressure and amount of fuel dose. In case of this fuel, a higher injection pressure and a smaller fuel dose result in shortening the self-ignition delay by $0.2 \mathrm{~ms}$. Lower fuel pressures in case of F3 fuel cause the highest delay values and the lowest flame development dynamics.

Similar conditions were observed for increased fuel pressure. That is, the high content of petrol significantly reduces the concentration of fuel in sprays, however, and does not allow for shortening the self-ignition delay. These 


No.
Type of fuel

Fig. 11 Images of self-ignition spots and early flame propagation for hydrocarbon fuels for variety of injection pressures and fuel doses

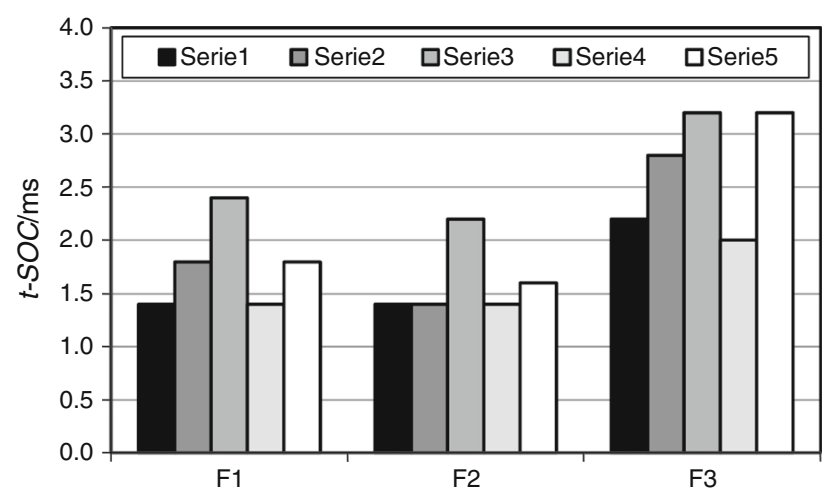

Fig. 12 Values of self-ignition delay for investigated fuels in five measurements series

properties arise from the opposite properties of fuels characterized by cetane or octane numbers.

Easy flammability conditions are confirmed in the earlier tests of F2 fuel. However, the cross-sectional and longitudinal analyses of sprays do not indicate clearly to the lower fuel concentration in the core planes (Fig. 6 and
7). For this reason, it might be declared that a mixture of diesel fuel with ethanol is a mixture with low self-ignition delay values, and thus, it is possible to get bigger engine speeds because of shorter duration of combustion. Quick evaporation of ethanol promotes low particulates and hydrocarbon emissions. The $30 \%$ content of DEE in the fuel does not influence significantly on the reduction of selfignition delay in relation to fuel F2. Analysis of images from Fig. 11 suggests that self-ignition spots occur when fuel sprays are still visible. In the case of F2 fuel, the ignition delay time is the same $(1.6 \mathrm{~ms})$, but the fuel in sprays has already evaporated (no lighting of sprays by appearing light-emitting flame).

Research on the self-ignition of fuels was repeated five times. The values obtained in subsequent attempts were correlated with the average values (Fig. 12). Certain nonrepeatability of results of self-ignition delays may result from the limited repeatability of charge movement in chamber, which significantly affects the rate of formation of self-ignition spots. However, the overall picture has been confirmed: Fuel F2 shows the highest propensity to combust, higher than F1 fuel (diesel).

Table 3 Engine operating conditions

\begin{tabular}{llll}
\hline Operating point & 1 & 2 & 3 \\
\hline Engine speed $(n)$ & $1000 \mathrm{rpm}$ & $1500 \mathrm{rpm}$ & $12 \mathrm{mg} / \mathrm{str}$ \\
Fuel dose $\left(q_{\mathrm{o}}\right)$ & $12 \mathrm{mg} / \mathrm{str}$ & $60 \mathrm{Mpa}$ & $27 \mathrm{mg} / \mathrm{str}$ \\
Fuel injection pressure $\left(P_{\text {inj }}\right)$ & $44 \mathrm{Mpa}$ & $0.1017 \mathrm{Mpa}$ & $120 \mathrm{Mpa}$ \\
Manifold pressure $\left(P_{\text {man }}\right)$ & $0.1017 \mathrm{Mpa}$ & $10^{\circ} \mathrm{ATDC}$ & $0.1213 \mathrm{Mpa}$ \\
Center of combustion $(C o C)$ & $9^{\circ} \mathrm{ATDC}$ & $0.540 \mathrm{Mpa}$ & $11^{\circ} \mathrm{ATDC}$ \\
Indicating mean effective pressure $(I M E P)$ & $0.538 \mathrm{Mpa}$ & $0.981 \mathrm{Mpa}$ \\
\hline
\end{tabular}



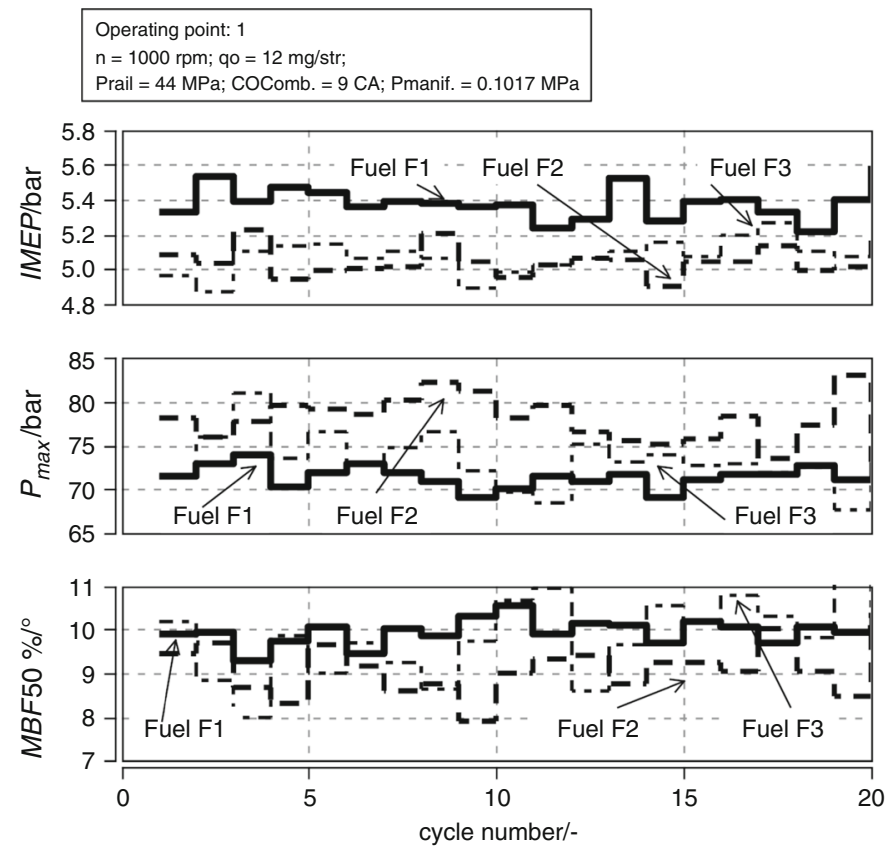

\begin{tabular}{|c|c|c|c|}
\hline \multirow{5}{*}{$\begin{array}{l}\text { Min } \\
\text { Mean } \\
\text { Max } \\
\operatorname{coV} \%\end{array}$} & $\begin{array}{l}\text { IMEP-F1 } \\
\text { BAR }\end{array}$ & $\begin{array}{c}\text { IMEP-F2 } \\
\text { BAR }\end{array}$ & $\begin{array}{l}\text { IMEP-F3 } \\
\text { BAR }\end{array}$ \\
\hline & 5.22 & 4.90 & 4.87 \\
\hline & 5.38 & 5.05 & 5.08 \\
\hline & 5.59 & 5.23 & 5.27 \\
\hline & 1.76 & 1.67 & 1.90 \\
\hline \multirow{5}{*}{$\begin{array}{l}\text { Min } \\
\text { Mean } \\
\text { Max } \\
\operatorname{coV} \%\end{array}$} & $\begin{array}{c}\text { Pmax-F1 } \\
\text { BAR }\end{array}$ & $\begin{array}{c}\text { Pmax-F2 } \\
\text { BAR }\end{array}$ & $\begin{array}{c}\text { Pmax-F3 } \\
\text { BAR }\end{array}$ \\
\hline & 68.98 & 73.13 & 67.68 \\
\hline & 71.33 & 77.92 & 73.33 \\
\hline & 73.91 & 82.99 & 80.92 \\
\hline & 1.71 & 3.42 & 4.11 \\
\hline
\end{tabular}

\begin{tabular}{|c|c|c|c|}
\hline & $\underset{\circ}{\mathrm{MBF} 50} \%$ & 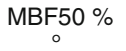 & 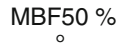 \\
\hline \multirow{4}{*}{$\begin{array}{l}\text { Min } \\
\text { Mean } \\
\text { Max } \\
\text { coV \% }\end{array}$} & 9.30 & 7.90 & 8.00 \\
\hline & 9.95 & 9.11 & 9.82 \\
\hline & 10.55 & 10.40 & 11.70 \\
\hline & 2.84 & 6.50 & 9.25 \\
\hline
\end{tabular}

Fig. 13 Operational indexes of the combustion process (operating point 1)

Fig. 14 Cylinder pressure (a) and heat release and rate of heat release (b) (operating point 1)

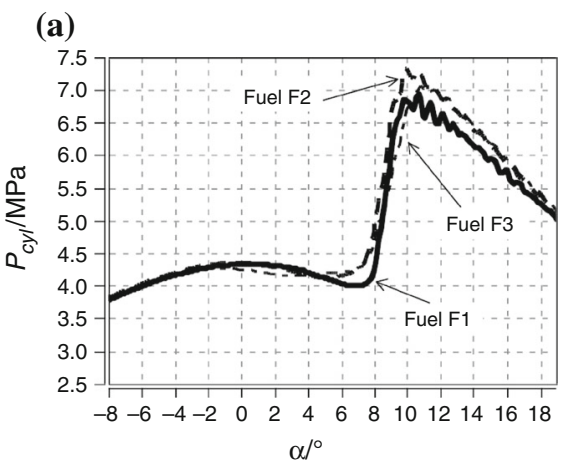

(b)

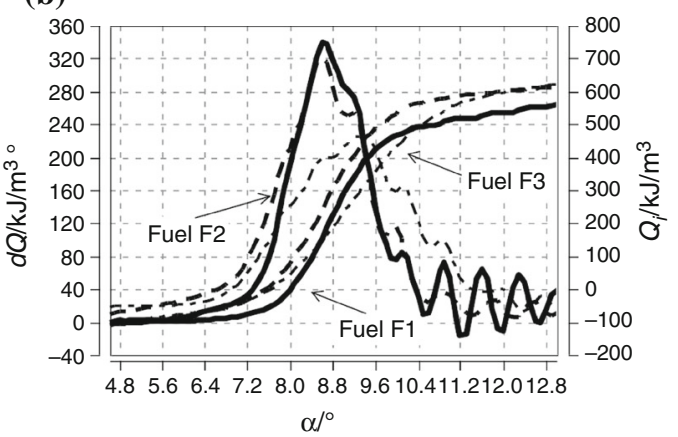

The conducted tests do not point out unequivocally to the advantages or typical disadvantages of the presented fuels. F3 fuel achieves the highest self-ignition delay, and it should be excluded at this stage of the tests; however, in order to obtain univocal results in different operating conditions of the engine, all of the fuels were used during the tests of the stand with one-cylinder engine.

\section{Tests of fuel usefulness in engine operating conditions}

The research on the parameters of the combustion process was conducted on a single-cylinder test stand. The 8-hole piezoelectric injectors were used (hole diameter $=$ $0.117 \mathrm{~mm}$ ) cooperating with the common rail system. The pressure of fuel injection and conditions of engine operation are presented in Table 3.

The thermodynamic analysis was conducted on the basis of the recorded 20 engine cycles. The values were averaged, and additionally, a low-pass filter of $40 \mathrm{kHz}$ was used to eliminate the undesirable effects associated with the way in which the combustion sensor is placed in the research engine (sensor denoted as GH12D with sensitivity of $15 \mathrm{pC} / \mathrm{bar})$.

The comparative analysis of the points of engine operation was conducted by correcting the fuel doses in such a way that their calorific energy was the same. It forced applying different injection times in order to obtain the same initial value of energy supplied to the engine. The data presented in Table 3 refer to diesel fuel. For the remaining fuels, minor corrections have been implemented. 
Fig. 15 Average values of cylinder pressure (a) and heat release and rate of heat release $(\mathbf{b})$ (operating point 2)
Fig. 16 Cylinder pressure (a) and heat release and rate of heat release (b) (operating point 3)
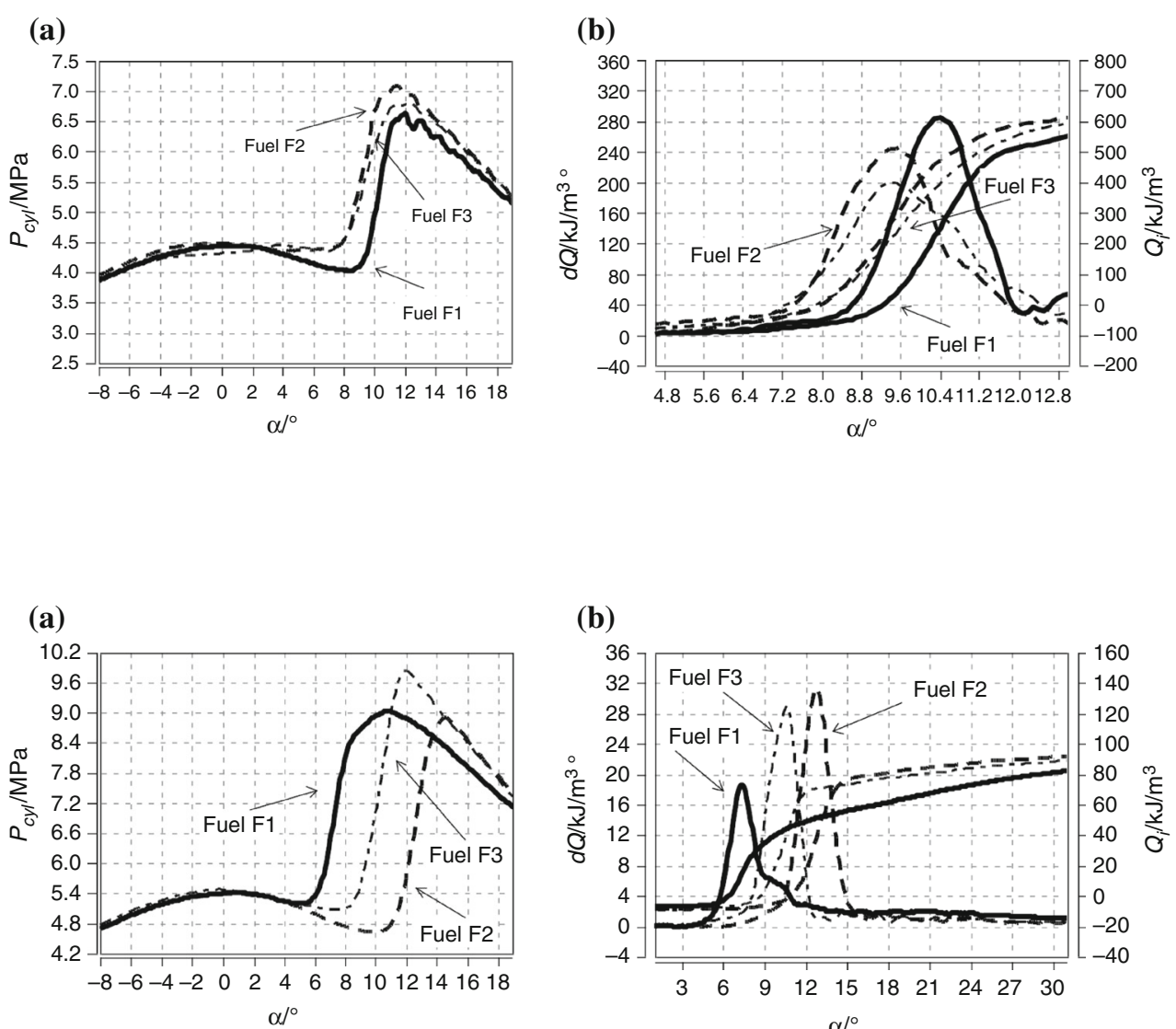

(b)

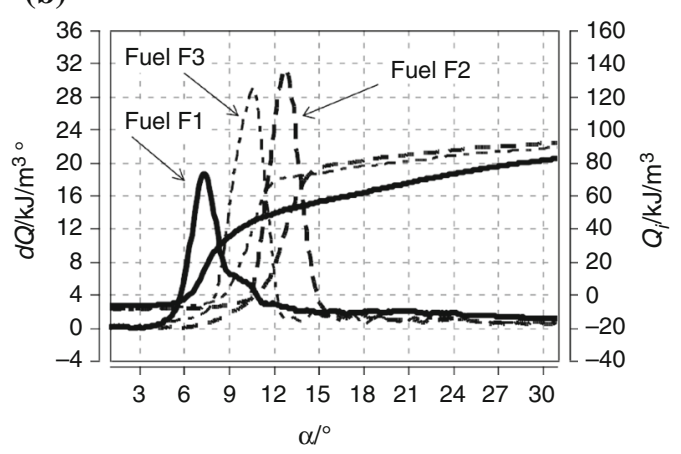

The data presented in Table 3 indicate the use of the combustion engine at low and medium loads and insignificant engine speeds. Such approach is applied in order to reflect the operation conditions of the self-ignition engine in urban traffic conditions. Such conditions are also typical during the type-approval tests, both NEDC (New European Driving Cycle) and WLTP (Worldwide Harmonized Light Vehicles Test Procedures) [23].

The indexes of engine operation recorded at the first measuring point indicate that the highest values of the indicated mean effective pressure (IMEP) are obtained for the diesel fuel. For the remaining fuels, this index is about $6 \%$ lower. It should be noted, however, that instability of the engine operation measured by coefficient of variation is in this case lowest during the combustion of F2 fuel $\left(C o V_{\text {IMEP }}=1.67 \%\right)$. In case of combustion of the other fuels, it is $1.76 \%$ for F1 fuel and $1.90 \%$ for F3 fuel. In engine tests, the $\mathrm{CoV}$ index for IMEP is accepted as the main index of engine operation instability [24, 25]. The analysis of instability (dispersion) was also conducted for the maximum pressure in cylinder and for the angle answering for $50 \%$ of burnt fuel dose (MBF50 \%-Mass Burn Fuel). This angle in the paper is also designated as the
CoC (center of combustion). On the basis of those two values, it might be concluded that the engine operation indexes show the highest stability for the base fuel (diesel oil). Significant dispersion of $\operatorname{CoV}_{\text {IMEP }}$ (of up to $10 \%$ ) during the analysis of the last index (MBF50 \%) should not raise any reservations, as it is associated with the uniqueness of the single-cylinder research engine operation. The results of the determined coefficient of variation for different engine operation parameters are presented in Fig. 13.

The direct analysis of the pressure in the cylinder indicates a rapid growth of this value during combustion of F2 fuel (Fig. 14a). It is also confirmed by high rate of heat release during combustion of this fuel. In case of F3 fuel, the combustion indexes are the worst, which is also confirmed by the presented earlier conditions of atomization of this fuel.

The change of the engine operating point improves the stability of combustion of F2 fuel. Value of $C o V_{\text {IMEP }}$ is similar to the value obtained during combustion of the diesel fuel (1.40\% for F1 fuel, $1.42 \%$ during combustion of F2 fuel and $1.95 \%$ during combustion of F3 fuel). The maximum values of combustion pressure are slightly 
higher than in case of diesel oil combustion $\left(P_{\max }\right.$ for $\mathrm{F} 1$ fuel is $7.064 \mathrm{MPa}$ ). For the remaining fuel mixtures F2 and $\mathrm{F} 3$, it is, respectively, $7.56 \mathrm{MPa}$ and $6.94 \mathrm{MPa}$. The attempt to obtain identical angle of $50 \%$ of burnt fuel dose results in slightly earlier combustion of the mixtures of alternative fuels (F2 and F3). The averaged values for 20 cycles show similar values of an angle at which the center of combustion is obtained $\left(C o C=10.1-11.3^{\circ} \mathrm{CA}\right.$ after TDC). The discrepancies of $\mathrm{CoC}$ for the averaged characteristics of pressure in the cylinder during combustion of the tested fuels amount to the value of about 0.5 degree of rotation of the crankshaft (Fig. 15a). This, however, results in varied characteristics of heat release rates. In case of alternative fuels mixtures (F2 and F3), the self-ignition delay is lower than in case of combustion of diesel oil. The initiation of the combustion process shown in Fig. 15b indicates slower heat release rate for alternative fuels mixtures (the shown characteristics of heat release rate are less steep).

Increase in the dose and pressure of the injected fuel (operating point 3 ) results in more significant differences in combustion of fuels. In case of alternative fuel mixtures, the obtained values of the maximum pressure in cylinder were higher (Fig. 16a), while values of IMEP were much lower, than in case of the base fuel (F1-0.981 MPa; F2 $0.797 \mathrm{MPa}$; F3-0.832 MPa). Instability of the engine operation was reduced during combustion of all types of fuels, which is proved by the low value of the coefficient of variation $C o V_{\text {IMEP }}$ amounting to $0.95 \%$ for diesel oil (fuel F1), $1.05 \%$ for F2 fuel, and $1.31 \%$ for F3 fuel.

Combustion of the alternative fuels F2 and F3 with the same calorific energy as the dose of F1 fuel makes it possible to obtain increased maximum values of pressure in cylinder compared with F1 fuel. Those values in case of F2 fuel are higher by about $2 \%$ compared with F1 and $11 \%$ higher during combustion of F3 fuel.

The increased fuel dose and different engine operating conditions contribute to the fact that obtaining the center of combustion of $11^{\circ}$ is burdened with a significant error amounting to $\pm 1.5^{\circ}$ compared with the averaged value that is 13.2 degrees after TDC. It results in significant non-uniformity amounting to $4-5 \%$ in obtaining this value. In case of F3 fuel, this value is the highest and amounts over $6.5 \%$.

The analysis of the averaged cycles shows high rate of heat release in the first phase of combustion in case of alternative fuels. Higher maximum combustion pressure results in significant delay of the combustion initiation. It should be noted, however, that the amount of the heat released is highest in case of diesel fuel.

The mixtures of alternative fuels are combusted extremely rapidly, so the assumed point of $50 \%$ of heat released is achieved very fast. As a consequence, it is necessary to delay the injection of the fuel injection in order to obtain the $50 \% \mathrm{MBF}$ for the angle of $11^{\circ}$ of $\mathrm{CA}$ after TDC. In Fig. 16 is visible a rapid growth in the heat released during combustion of all analyzed types of fuels. For mixtures of alternative fuels, the change in the rate of heat released is so rapid that establishing the fixed point of $50 \%$ of burnt fuel dose is difficult. Additionally, combustion of alternative fuel mixtures shows dispersion of many indexes, which in case of MBF50 \% value amounts to $6 \%$. However, for diesel oil (F1), the value of dispersion is also high and amounts to $4 \%$. Additionally, in case of fuel mixtures, the dispersion of the maximum values of combustion pressure obtained was $50 \%$ higher than in case of diesel fuel.

\section{Conclusions}

The research reported here shows the applicability of alternative fuels in combustion systems of CI engines. These fuels are characterized by various physical and chemical properties, which lead to different conditions of fuel atomization and combustion. In particular, it should be noted that:

(a) Mean values of fuel atomization indexes do not indicate clearly the existence of significant differences in their values; this note mainly applies to fuel spray penetration at different injection pressures and injected doses;

(b) For lower values of the injection pressure, the differences in spray penetration are increasing for some fuels; about $0.8 \mathrm{~ms}$ after the start of the injection fuel containing ethanol has a much larger surface area of sprays than the other fuels;

(c) Evaluation of fuel distribution in sprays indicates that fuels with ethanol have higher rate of evaporation;

(d) Fuel containing ethanol shortens the self-ignition delay, causes faster evaporation of fuel, and as a consequence the reduction of emissions of toxic compounds is being expected.

Combustion of alternative fuels with the addition of ethanol results in high combustion rate, which in case of fixed centers of combustion contributes to quite delayed ignition of the mixture. Such situation led to reduction of the kinetic phase of combustion during the compression stroke, which should have resulted in the reduction of the concentration of nitric oxides in the combustion chamber. However, the kinetic phase occurring during combustion of these fuels was just shifted toward the delayed self-ignition. It will result in the reduction of soot emission and formation of particles. Significant kinetic phase occurring 
after TDC might lead to the reduction of the maximum temperature of combustion in the cylinder (due to large instantaneous volume of the chamber). But as a consequence of further decompression, it leads to the drop of pressure in the cylinder and to rapid termination of the combustion. This situation is presented in Fig. 16a, where the rate of decompression pressure change in case of mixtures of alternative fuels is much more significant than in case of conventional fuel.

Acknowledgments The research presented in this paper was performed within the European Research Project PowerFul FP7, grant agreement No. 234032, POWERtrain for Future Light-duty vehicles. The authors are grateful to EU for funding the work and to all persons, who have their contribution in this study and laboratory works.

Open Access This article is distributed under the terms of the Creative Commons Attribution 4.0 International License (http:// creativecommons.org/licenses/by/4.0/), which permits unrestricted use, distribution, and reproduction in any medium, provided you give appropriate credit to the original author(s) and the source, provide a link to the Creative Commons license, and indicate if changes were made.

\section{References}

1. Weißner M, Wrede K, Watzl S, Menzel T, Schüttenhelm M, Klüting CB, Frambourg M. Powerful-development of engine and vehicle to realise low $\mathrm{CO}_{2}$-emissions. Combust Engines. 2014;157(2):3-21.

2. Pielecha I, Borowski P, Czajka J, Wisłocki K, Kaźmierowski J. Combustion process shaping by use of different strategies of multiple fuel injection in a CI model engine. J Therm Anal Calorim. 2014;. doi:10.1007/s10973-014-4139-y.

3. Pielecha I, Maslennikov D, Wisłocki K. Optical research of spray development of E85 fuel in high pressure gasoline direct injection system. SAE Paper 2010-01-2285. 2010. doi:10.4271/2010-012285.

4. Wisłocki K, Pielecha I, Maslennikov D, Czajka J. Analysis of bio-diesel spray atomization in common-rail piezo-injector system. SAE Paper 2010-01-2282. 2010. doi:10.4271/2010-01-2282.

5. Pielecha I, Wisłocki K, Czajka J, Maslennikov D. Determination of the self-ignition delay for different types of diesel fuels. W2P014, 34th International Symposium on Combustion, Warsaw 2012.

6. Pielecha I, Czajka J, Wisłocki K, Borowski P. Research-based assessment of the influence of hydrocarbon fuel atomization on the formation of self-ignition spots and the course of pre-flame processes. Combust Engines. 2014;157(2):22-35.

7. Pielecha I, Borowski P, Cieślik W. Investigations into highpressure diesel spray-wall interaction on reduction of exhaust emission from DI diesel engine. SAE Paper 2014-01-1250. 2014. doi:10.4271/2014-01-1250.

8. Shi X, Yu Y, He H, Shuai S, Wang J, Li R. Emission characteristics using methyl soyate-ethanol-diesel fuel blends on a diesel engine. Fuel. 2005;84:1543-9. doi:10.1016/j.fuel.2005.03. 001 .
9. Satgé de Caro P, Mouloungui Z, Vaitilingom G, Berge JC. Interest of combining an additive with diesel-ethanol blends for use in diesel engines. Fuel 2001;80,565-74. doi: 10.1016/S00162361(00)00117-4.

10. Hansen AC, Zhang Q, Lyne PWL. Ethanol-diesel fuel blends-a review. Biores Technol. 2005;96:277-85. doi:10.1016/j.biortech. 2004.04.007.

11. Wadumesthrige K, Ng K, Salley S. Properties of butanol-biodiesel-ULSD Ternary Mixtures. SAE Int J Fuels Lubr. 2010;3(2):660-70. doi:10.4271/2010-01-2133.

12. Kinoshita E, Hamasaki K, Imabayashi R. Diesel combustion characteristics of biodiesel with 1-butanol. SAE Int J Fuels Lubr. 2012;5(1):558-65. doi:10.4271/2011-32-0590.

13. Biradar C, Subramanian K, Dastidar M. Performance improvement and emissions reduction of a DI diesel engine for use of Karanja biodiesel-diesel blend (B20) using diethyl ether. SAE Paper 2011-26-0004. 2011. doi:10.4271/2011-26-0004.

14. Iranmanesh M, Subrahmanyam J, Babu M. Potential of diethyl ether as supplementary fuel to improve combustion and emission characteristics of diesel engines. SAE Paper 2008-28-0044. 2008. doi:10.4271/2008-28-0044.

15. Iranmanesh M, Subrahmanyam J, Babu M. Potential of diethyl ether as a blended supplementary oxygenated fuel with biodiesel to improve combustion and emission characteristics of diesel engines. SAE Paper 2008-01-1805. 2008. doi:10.4271/2008-011805.

16. Cui X, Helmantel A, Golovichev V, Denbratt I. Combustion and emissions in a light-duty diesel engine using diesel-water emulsion and diesel-ethanol blends. SAE Paper 2009-01-2695. 2009. doi:10.4271/2009-01-2695.

17. Park SH, Cha J, Kim HJ, Lee CS. Effect of early injection strategy on spray atomization and emission reduction characteristics in bioethanol blended diesel fueled engine. Energy. 2012;39:375-87. doi:10.1016/j.energy.2011.12.050.

18. Baumgarten C. Mixture formation in internal combustion engines. New York: Springer; 2006.

19. Park SH, Suh HK, Lee CS. Nozzle flow and atomization characteristics of ethanol blended biodiesel fuel. Renew Energ. 2010;35:144-50. doi:10.1016/j.renene.2009.06.012.

20. Yamamoto S, Watanabe S, Komada K, Sakaguchi D, Ueki H, Ishida M. Study on combustion and soot emission of ethanol or butanol blended with gas oil in a direct injection diesel engine, SAE Int J Fuels Lubr 2013. doi:10.4271/2013-32-9112.

21. Prado AGS, Andrade RDA, Braga JWB, Suarez PAZ. Thermal diesel-like analysis. Quality control by thermal and chemometric analysis. J Therm Anal Calorim. 2012;110:865-72. doi:10.1007/ s10973-011-1862-5.

22. Tutunea D. Thermal investigation of biodiesel blends derived from rapeseed oil. J Therm Anal Calorim. 2013;111:869-75. doi:10.1007/s10973-012-2213-x.

23. Weinowski R, Wittek K, Dieterich C, Seibel J. Variable compression ratio for gasoline engines. MTZ Worldw. 2012;73(5): $22-32$.

24. Lee C, Tomita E, Lee K. Characteristics of combustion stability and emission in SCCI and CAI combustion based on direct-injection gasoline engine. SAE Paper 2007-01-1872. 2007. doi:10. 4271/2007-01-1872.

25. Cong S, McTaggart-Cowan G, Garner C. Effects of fuel injection parameters on low temperature diesel combustion stability. SAE Paper 2010-01-0611. 2010. doi:10.4271/2010-01-0611. 